\title{
Debating the Role of Patriarchy in the Incidence of Gender-based Violence in Jordan - Systematic Review of the Literature
}

\author{
Nour Daoud
}

\begin{abstract}
Patriarchy continues to thrive in Jordan where malecontrolled values are still entrenched in a society that is suffering from upsetting percentages of Gender-based Violence (GBV). This paper is a systematic review of the literature with an attempt to evaluate and interpret all available research evidence relevant to determining the extent to which patriarchy contributes to the occurrence, re-occurrence and continuation of GBV against women in Jordan. Twenty-one (21) full-text articles were selected for the indepth review due to meeting the established criteria for inclusion. (81) percent of articles included primary data while (19) percent included secondary data. Analysis of data was based on a specific extraction form that was developed using the 'Excel' to respond to the main goal of the paper. Interpretation of data was built based on theoretical explanation of different feminism schools to the relationship between patriarchy and gender-based violence against women. Findings show that (33) percent of the selected articles affirm that the patriarchal standpoint best explains the incidence of gender-based violence in Jordan. Apart from the limited number of articles that were found debating this argument and the low percentage of articles that acknowledged the role of patriarchy in the incidence of gender-based violence in Jordan, this paper breaks the ice to implement future empirical studies on this subject. Also, it is an invitation for all Jordanian women to unite their efforts in order to eradicate all forms of victimization against them.
\end{abstract}

Keywords - Honor-based Violence, Intimate Partner Violence, Middle-East, Street Harassment

\section{INTRODUCTION}

In 1993, The United Nations Declaration on the Elimination of Violence against Women (DEVAW) defined gender-based violence as: "any act that results in, or is likely to result in, physical, sexual or psychological harm or suffering to women, including threats of such acts, coercion or arbitrary deprivation of liberty, whether occurring in public or in private life".[1] Many women from all over the world suffered and are suffering from several forms of gender-based violence that are occurring whether at the level of family or within the general community or are perpetrated by the state agents. Despite Jordan's continuous commitment to human rights and gender equity through ratifying international conventions, providing equal opportunities and developing programs related to women's empowerment, gender gaps still exist in different

Nour Daoud is a $\mathrm{PhD}$ candidate of Social Sciences: Interaction, Communication, and Cultural Construction at the University of Padova, Italy. socio-economic spheres of the Jordanian society, and this, weakens women's position in the society and increases her vulnerability to violence. According to UNFPA's fact sheet on Gender-based violence that was published in May 2017, "79 percent is the occurrence of domestic violence among women in Jordan who are aged between 18-64 years old, while around 20 to 30 women lose their lives because of the so-called 'honor' killing every year in Jordan". [2]

The Jordanian society is a patriarchal one. The status quo of male authority and power is still dominant in the Jordanian society, while unfortunately, women are taking inferior and subordinated positions. A clear example of the aforesaid, is the issue of granting Jordanian nationality to children of Jordanian mothers; a child born to a non-Jordanian mother with Jordanian father is given citizenship automatically, however if the mother is Jordanian and the father is not, there is no such law. Another example, is the political participation of women in Jordan where the political positions of power are still controlled by men. For instance, in the 2016 parliamentary elections, women only received (20) seats in the election with a (15.4) percent of all seats. This percentage is very low in comparison to other Arab countries like Sudan (31) percent, Algeria (26) percent, Iraq (25) percent, United Arab Emirates (23) percent and Saudi Arabia (20) percent. Women and feminist movements in Jordan are playing an integral role to empower women socially, politically and economically, but despite their significant efforts towards achieving gender equity, the patriarchal system is still pulling their efforts down and pushing to preserve subjugation of women in all sectors of life. This paper is a systematic review of the literature that attempts to evaluate and interpret all available research evidence relevant to the question of: To what extent does patriarchy play a role in the incidence of gender-based violence against women in Jordan? It seeks to determine the extent to which patriarchy contributes to the occurrence, reoccurrence and continuation of GBV in Jordan. Arguments in this article are built based on theoretical expositions and conclusions of studies on related themes. Also, it will give insights on how the relationship between patriarchy and gender-based violence has been theorized. The paper is structurally divided into five parts - Part 1 consists of an introduction; Part 2 discusses the theoretical framework and literature review on the origin and impact of patriarchy on 
women, and how it is interlinked with GBV; Part 3 focuses on Gender-based violence in Jordan; Part 4 sheds the light on the methodology and findings of the systematic literature review; while Part 5 provides conclusion and recommendations toward a way forward.

\section{CONCEPTUALIZATION OF PATRIARCHY}

The patriarchy term was initially used to describe the position of the father as a household head but it has progressively been used to refer to the systemic organization of male hegemony and female subservience; Weber (1974), for example, used the term patriarchy "to refer to a system of government in which men ruled societies through their position as heads of families" [3]. According to Lerner (1986), patriarchy is "the manifestation and institutionalization of male dominance over women and children in the family and the extension of male dominance over women in society in general" [4]. Hartmann (1976) confirmed that patriarchy is "a set of social relations which has a material base and in which there are hierarchical relations between men, and solidarity among them, which enable them to control women" [5]. Activists, like Millet (2000), questioned the origins of patriarchy [6], while Mitchell (1974), confirmed that patriarchy as a system supports hierarchicalism, male dominance and egotism. she also emphasized that patriarchy expects from women to always aggrandize men and support them emotionally. Mitchell agreed with Freud's idea that women within the patriarchal social world, are seen as feminine who take pleasure in being dominated and excluded from decision-making in the public sphere [7]. The French philosopher Foucault (1973) claimed that the family is the foundation of patriarchal society [8], and the authors Dobash (1979) agreed with him by stating that the family is one of the most patriarchal institutions in the society [9]. Walby (1990) categorized patriarchy in six social structures which are: paid work, housework, sexuality, culture, violence, and the state where their inter-relationships create different forms to understand the depth of women's subordination [10]. Similarly, Gewn Hunnicutt (2009) classified patriarchy at two levels; the macro level which includes governmental and religious institutions and the micro level which encompasses interactions between families or organizations [11]. Dobash and Dobash (1979) and Valentine Moghadam (2004), argued that the position of women in society as subordinate to men, has been historically supported and reinforced by legal, political, economic and ideological structures [12], these structures directly or indirectly maintain and reinforce the ideology and reality of men's authority over women and foster the acceptance of men's use of violence against women.

In sum, patriarchy is a social structure in which males dominate and control. Patriarchy is made up of institutions that eliminate women from participation in, or contact with spaces of higher authority. Patriarchy is the first structure of domination, subordination and exclusion that has established itself in different sectors of a variety of different societies, "even if it is not explicitly defined to be by their own constitutions and laws, most contemporary societies are in practice patriarchal" [13].

\section{THEORIZATION OF PATRIARCHY AND GENDER-BASED VIOLENCE}

The concept of patriarchy was primarily developed and used by feminist theories to clarify the domination of males in modern societies [14]. Feminist theory explains patriarchy as an unfair social system that imposes gender roles and is cruel to both men and women. Also, "it characterizes patriarchy as a structure that includes social, political, or economic mechanisms in which evoking male dominance over women" [15].

Liberal feminists contend that patriarchy is the prevailing cause and explanation of gender-based violence. "Liberal feminists believe that the structural inequality between men and women generates a culture in which violence against women is tolerated" [16]. Liberal feminists consider that the civil and political equality is the solution to improve women's status in the society and end women's situation of subordination. From the other side, socialist feminists, argue that the subordinated status of women is influenced by their socio-economic status in the society, which has to be changed in order for women to improve their situation and to be more empowered. Socialist feminists view that capitalism strengthens patriarchy by accumulating money and power in the hands of men. They consider that the mixture of both capitalistic economy and patriarchy is the main barrier to achieve women's equality. The dual system theory also views both patriarchy and capitalism as one interlinked system of control and economic relations in the search of benefit. Marxist feminism confirms that classism rather than sexism is the main instrumental element behind the harassment and repression of women. Marxist feminism focuses on the importance of changing the economic realm and the conventional family structure in order to improve the situation of women and eradicate violence against them. On the contrary, radical feminism considers patriarchy the most fundamental form of domination and it precedes capitalism. For many radical feminists like Brownmiller's (1975) and Daly's (1978), patriarchy can be sustained by men who possess women's sexuality and who keep them in the state of fear. Generally, the radical feminists see that "the family and the institution of heterosexuality which is derived upon the conventional family are key in understanding patriarchy and women's subordination" [17]. Black feminists call for a new concept of patriarchy which is adaptable enough to comprehend the variations in women's experiences. They argue that the way to end violence against women is by interlocking structures of oppressions like racism and classism. Crenshaw (1989), through her intersectional approach, addressed the manner in which racism, patriarchy, class oppression and other discriminatory systems interlocked to create inequalities that foster oppression against women. 
Similarly, postcolonial feminism focuses on studying both patriarchy and the colonial power in many countries even after they have achieved independence as a strategy to comprehend women's oppression and subordination. Postcolonial feminist, Lord (1983), in her essay entitled "The Master's Tools Will Never Dismantle the Master's House", explained how western feminism failed to make positive change for third world women by using the same tools that are used by the patriarchal system to oppress women [18]. Furthermore, standpoint feminism acknowledges that women by raising their voices, telling their own suffering stories, and by interpreting their realities, they can overcome patriarchy and the era of oppression against them. Moving to the Islamic feminism that has recently arose as a challenge to patriarchy in Muslim societies. The majority of Islamic feminists claim that the difficulties faced by Muslim women are generally the result of erroneous male interpretations of the principles of Islam that embed patriarchal norms within the family and society. In reexamining the Qur'an and hadith, Islamic feminists are making forceful arguments that Islam does not excuse harmful violence against women. The solution referring to them is by utilizing an intersectional feminist analysis to challenge patriarchy and understand the issue of gender-based violence in Islamic communities. On a different note, Arabic feminism believes that patriarchy is powerful in the Arab world because of kinship values and relationships, where the impact of these values on women has been manifested through rape, sexual exploitation, and domestic violence. El Saadawi (2007) in her novel entitled "God Dies by the Nile" argued that women are victims of the patriarchal class system. She tried to explain to the reader that "patriarchy emerges as a system with political, economic, social, cultural and psychological manifestations" [19].This oppressive system according to El Saadawi is the real cause behind the suffering of women.

The psychological perspective claims that patriarchy cannot clarify the prevalence of gender-based violence as feminists postulate. However, they reflect that patriarchy might be one of factors that causes violence against women, especially if the setting of incidence is very patriarchal. The ecological perspective agrees with the psychological, the postcolonial and the black feminism position that patriarchy is not the sole cause for the occurrence and re-occurrence of gender-based violence against women. Heise (1998), in his article entitled "Violence against women: An Integrated Ecological Framework", argued that no one factor alone causes violence but rather that a number of factors combine to raise the likelihood that a particular man in a particular setting may act violently toward a woman. The factors that Heise focused on in his ecological model are: the biological and personal history, the context, the institutions and social structures, and finally the economic and social environment including the norms and practices that define women as inferior to men.

In a nutshell, the majority of theoretical frameworks consider that patriarchy is the main factor that contributes to the subordination and violence against women or believe that patriarchy is one of many other factors that interlink together and cause increase in the incidence of gender-based violence against women.

\section{GENDER-BASED VIOLENCE IN JORDAN}

Today, gender-based violence against women is a vital issue facing the Jordanian government, especially after the concerns that were raised by the Committee on the Elimination of Discrimination against Women (CEDAW) in February 2017 about Jordan's regression on gender equality, remarking the drop in ranking to the 140th position in comparison to the previous years. Also, the committee urged Jordan to actively use temporary special measures to stand against customs, stereotypes and patriarchal beliefs which held women back from full participation in public, political and economic life. The Gender-based violence (GBV) is widespread in Jordan and it is reaching upsetting proportions especially after the Syrian refugee crisis. In this paper, the light will be shed on three types of GBV that are mostly common in the Jordanian setting in order to explore the role of patriarchy in the incidence of GBV in Jordan.

\section{V.METHODOLOGY}

This study utilizes the literature review as a mode of analysis to investigate the role of patriarchy in the incidence and re-incidence of gender-based violence in Jordan through the analysis of academic literature, previous studies, and grey literature like the Jordanian government documents and official statements, UN reports, press releases, statistics, and related reports and speeches written in the field of genderbased violence and patriarchy in Jordan.

\section{A. Mechanism of Search}

The search of the literature was implemented during the beginning of October until the end of November 2017 utilizing numerous resources. Published literature was searched for through the web search engine "Google Scholar", the digital library "JSTOR", the US national library "PubMed", the online database platform "Popline", and through the online archive of "SAGE Publications". Also, a deep search was made to review published reports and statistics from UN agencies, advocacy and non for profit organizations like UNFPA, UNDP, UN Women, WHO and Human Rights Watch through their website materials and the web-based index of United Nations document "Access UN". In this vein, it is important to mention that the selection of an array of nonhomogeneous sources for collecting articles was with an intention to get different scientific and standard international political perspectives on the phenomenon of gender-based violence.

The key sentences/topics used to look for articles and publications were "Gender-based Violence in Jordan", "Violence against Women in Jordan", "Honor/Honour Killings in Jordan", "Honor/Honour-based Violence in Jordan", 
"Intimate Partner Violence in Jordan", "Street Harassment in Jordan", "Patriarchy and Violence against Women in Jordan", "Patriarchy and Violence against Women in Muslim Societies".

\section{B. Outcome of Search}

Sixty (60) search results were firstly scanned, (26) articles were found through "Google Scholar", (14) articles from "SAGE Publications", (6) articles from "PubMed", (5) articles from "Popline", (5) articles from "JSTOR" and (4) reports from organization and UN agencies websites. All of the (60) articles and reports included at least one of the aforementioned key topics. Google Scholar results were viewed until (250) results, however, the search in the remaining platforms was continued until the end of relevant articles.

Twenty-one (21) full-text articles were selected for the indepth review due to meeting the established criteria for inclusion or exclusion. The selection criteria for inclusion was developed by the author and comprise of: a) relevance to the goal of the article which is to investigate the role of patriarchy in the incidence of Gender-based Violence in Jordan in specific b) cogency and suitability of the methodology c) quality of collecting, analyzing and reporting process.

It is worth mentioning that all articles were published in the English language and no restrictions were made on the nationality of the author(s) or the year of publication. Three authors had more than one article that met the inclusion criteria (Haj-Yahia, Oweis, and Gharaibeh). (52.4) percent of the written articles were published during or after 2010 and (47.6) percent of articles were written before 2010. The majority of articles answered the questions of (Who, What, Where, When) rather than answering the questions of (Why, How). (81) percent of articles were based on empirical research and (19) percent were theoretical-based articles. (53) percent of the empirical articles utilized the quantitative methodology for collecting data, while (47) percent of empirical articles utilized the qualitative methodology. (90) percent of articles discussed gender-based violence in Jordan in specific while (10) percent focused on the Muslim and Arab community in general. (81) percent of articles included primary data while (19) percent of articles included secondary data.

The articles that met the selection criteria under the paper's three main themes - Honor-based Violence, Intimate Partner Violence (IPV) and Street Harassment are: (Eisner and Ghuneim, 2013); (Cinthio and Ericsson, 2006); (Chesler and Bloom, 2012), (Hartman, 2010);(Haj-Yahia, 2002); (HajYahia, 2005); (Al Matalka and Al Hussainat, 2013); (Sheeley, 2007); (Faqir, 2001); (Al Rawhi, 2016), (Kulczycki and Windle, 2011); (Becknell, 2005); (Btoush and Haj-Yahia, 2008); (Haddad et al., 2011); (Linos et al., 2010); (Sanaa Abujilban et al., 2015); (Clark et al., 2009); (Gharaibeh and Oweis 2009); (Oweis et al., 2009); (Mahadeen,2017); (Truluck 2015).

\section{Analysis of Data}

The analysis of data starts by reading the full text of each article identified for inclusion in the review and extract the pertinent data which answer the question of this paper using a specific form. The data extraction form is developed to include the following fields: Name of Article, Reference (Author, Year, Journal Citation), Location, Sample Size, Duration of Study, Method of Collection, Method of Analysis and Interpretation, General Results, Results Pertaining the Goal of the Paper.

The last field of the form 'Results Pertaining the Goal of the Paper' is categorized into three statements, which are:

1. The role of patriarchy in the incidence of gender-based violence in Jordan is strongly confirmed in the article. (This means that the article confirms that patriarchy plays an important role in the incidence of GBV and it is one of the article's main findings)

2. The role of patriarchy in the incidence of gender-based violence in Jordan is fairly confirmed in the article. (This means that the article highlights that patriarchy plays a role in the incidence of GBV in the literature review of the article)

3 . The role of patriarchy in the incidence of gender-based violence in Jordan is weakly confirmed in the article. (This means that the article does not relate the incidence of GBV to patriarchy)

\section{FINDINGS AND DISCUSSION}

The findings of the paper are presented to respond to the question of the paper which is: To what extent does patriarchy play a role in the incidence of gender-based violence in Jordan? The findings are articulated as part of the paper's three main themes: Honor-based Violence, Intimate Partner Violence (IPV) and Street Harassment.

\section{A. Honor-based Violence (HBV)}

The notion of 'honor' has played a protuberant role in the anthropology of the Middle East, North Africa, and of the Mediterranean region. In Jordan, 'honor' crimes against women "make up one-third of all the violent deaths" [20]. Human Rights Watch (2001) defines 'honor' killings as follows:

"Honor killings are acts of vengeance, usually death, committed by male family members against female family members, who are held to have brought dishonor upon the family. A woman can be targeted by (individuals within) her family for a variety of reasons, including: refusing to enter into an arranged marriage, being the victim of a sexual assault, seeking a divorce-even from an abusive husbandor (allegedly) committing adultery. The mere perception that a woman has behaved in a way that "dishonors" her family is sufficient to trigger an attack on her life" [21].

Jordan, although in the processes of modernization, still solicits a patriarchal power base, leaving the concept of 'honor' deeply rooted in kinship relations and familial bonds [22]. There are approximately (20) to (30) 'honor' crimes per 
year in Jordan, however, the percentage is on the rise. The Sisterhood, which is a Global Association, that tracks women's rights issues in the country, noted a (53) percent rise in such violence in 2016 compared to 2015 . In only one week, during October 2016, Jordanian media reported five women killed in the name of 'honor' in Jordan [23].

The data related to honor-based violence against women is often difficult to analyze because of the great number of 'honor' killings that happen, but are never reported. This can be justified due to the fact that some families hide the incident of honor-killing against the female victim of the family as a means of protecting the male killer in the family. Also, many women who were subjected to violence because of 'honor', refuse to report being addressed to violence for fear of killing, or fear that the legal system will not guarantee justice to them or fear of spending years in prison as a protective custody or fear of society's view of them if they complain against a male member of their household. It is important to highlight that the Jordanian government is playing a prominent role in criminalizing 'honor' killing and that was clear through the establishment of special court for prosecuting 'honor' crimes in 2009 and lately, the abolishment of the law that allowed rapists to avoid prosecution by marrying their victims, but this is the only first step in protecting women's right in Jordan, where the second step should be done, through abolishing the exemption clauses that give lenient sentences to murders in the cases of 'honor' killing.

This paper will build its argument only on the official data and on the analysis of the ten articles that were included based on the results of the systematic research. The selected articles will help to develop a debate that relates the occurrence of honor-based violence to patriarchy in Jordan.

Eisner and Ghuneim (2013), examined in their article the attitudes towards 'honor' crimes amongst a sample of (856) ninth grade students from (14) schools in Amman, Jordan. Findings showed that about (40) percent of boys and (20) percent of girls believe that killing a daughter, sister, or wife who has dishonored the family can be justified. Findings suggested that attitudes in support of 'honor' killings are more likely amongst adolescents who have patriarchal world views [25].

Furthermore, the national public opinion survey that was implemented by Sheeley (2007) in Jordan, indicated that (33) percent amongst the (200) respondents, knew somebody who had been threatened with an 'honor' killing, (28) percent knew personally somebody who had died in an 'honor' killing and (4) percent of the respondents said that an 'honor' killing had happened in their extended family. Also, the article showed that (72) percent of respondents linked the occurrence of 'honor' crimes to the patriarchal culture in Jordan while (69) percent believed that the tribal customs and norms are the reason behind 'honor' killings in Jordan [26].

According to Faqir's article (2001), 'honor' killings are clearly connected to the women subordination in Jordan. Faqir added that the dominant biased culture in Jordan can't be changed without implementing a holistic program for sociolegal and political reform [27]. Likewise, Cinthio and Ericsson (2006), concluded that 'honor' killing in Jordan is viewed as a result of combining Islam and culture in the form of tribal patriarchy where they interact to make violence against women possible. They commented at the end of their study that "human rights activists still have a hard battle to fight in order to change the perceptions of gender roles and relations, to generate a reinterpretation of the concepts of democracy and justice, and to bring an end to the cruel custom of 'honor' violence" [28]. From the other side, Al Rawhi (2016) emphasized that the occurrence of 'honor' killing has nothing to do with Islam as "many Islamic leaders and scholars condemn the practice and deny that it is based on religious doctrine." Therefore, in his article, he drew on the conclusion that honor killing is related to cultural practices and weak law enforcement [29].

Additionally, Kulczycki and Windle (2012) in their article "Honor Killing in the Middle East and North Africa", stated it clearly that 'honor' killing can be eliminated in the MENA region by tirelessly working to achieve gender equality. Also, they claimed that "the primary reasons why 'honor' killings are seen to occur in the patriarchal and patrilineal societies of the MENA region is because they are a mechanism for maintaining strict control over women" [30]. Similarly, Chesler and Bloom (2012), debated that 'honor' killings tend to be prevalent in patriarchal societies where individual rights are bounded by communal solidarities, patriarchal authority structures, and tribal beliefs [31]. From her side, Mahadeen (2016), affirmed that 'honor' crimes in the Jordanian context are normalized [32]. Also, Becknell (2005) emphasized in the conclusion of his article that Jordanian women continue to be abused and murdered in the name of patriarchy and 'honor'[33].Finally, Hartman (2010) confirmed that the dominance of the patriarchal family and the inability of the country to experience economic growth are strong factors to the continuation of 'honor' crimes in Jordan [34].

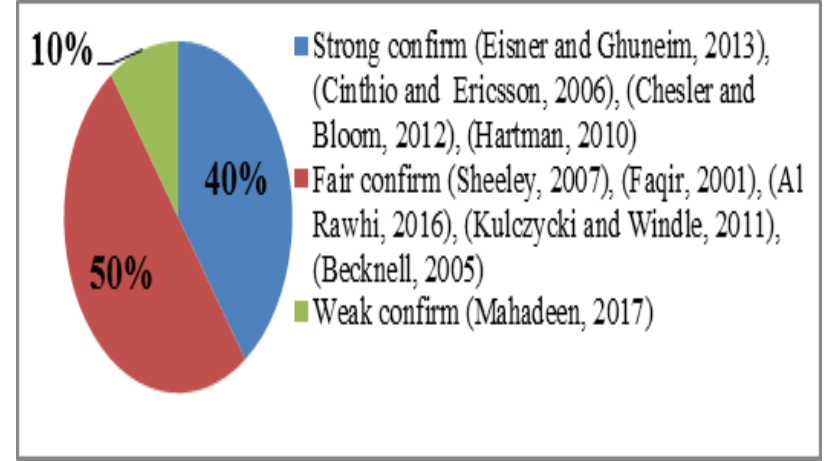

Fig. 1: Percentage of articles that confirm the role of patriarchy in the incidence of honor-based violence in Jordan based on a developed scale of (Strong, Fair, Weak)

Figure 1 shows that (40) percent of the selected articles under the category of honor-based violence, strongly confirm the role of patriarchy in the incidence of honor-based violence in Jordan and this was clearly referenced in the findings and 
conclusion part of articles, while (50) percent of the selected articles discuss the relationship between patriarchy and honorbased violence only as part of the literature and theoretical review. (10) percent of the articles do not evidently confirm the role of patriarchy in the occurrence of honor killings in Jordan. It is worth mentioning that the study referenced number [28] is the sole article that explicitly cited the word "patriarchy" in its title.

In light of the above, honor-based violence remains a major issue in Jordan, but still limited scientific papers are being done for critically analyzing this social phenomenon and its relationship to patriarchy. The articles referenced as [27], [33], [34], [30], [25] emphasized that the Jordanian society needs to work on challenging patriarchy through growing economically, focusing on the education sector and conducting public awareness campaigns as a way to actively promote change in the socio-culture mindsets which boost this phenomenon, and ensuring that the legal and policy frameworks are strict towards any act of violence.

\section{B. Intimate Partner Violence (IPV)}

Intimate Partner violence (IPV) is one of the most common forms of violence against women which includes physical, sexual, and emotional abuse and controlling behaviors by an intimate partner [35]. IPV against women is a worldwide problem, with lifetime prevalence between (8) percent and (65) percent in developing countries and about (23) percent in high-income countries [36]. IPV is increasingly being recognized as a significant health problem in terms of prevalence and acceptance in Jordan where "(14) percent of partnered women had experienced intimate partner violence and/or sexual violence during 2013" [37]. It is important to note that many IPV cases in Jordan remain un-reported because many Jordanian consider it a private and family issue. Also, many women do not perceive themselves as victims of IPV. Ten articles were met the selection criteria under the category of intimate partner violence (IPV) and discuss the issue of IPV in Jordan with relation to patriarchy. Before delving with the articles, it is essential to explain that the most common perpetrators of IPV against women are male husbands, partners or ex-partners while the perpetrators of HBV against women are any male member of the core or extended family of the female victim. Another point is that the occurrence of $\mathrm{HBV}$ against women is all the time linked to the 'feminine' honor code.

In the article of Btoush and Haj-Yahia (2008), results showed that among the (260) Jordanian participants, almost half reported that they knew of abused women among their relatives, neighbors, or friends, and primarily attributed the abuse on the women's actions or on both partners. According to the authors, the results of this study can be interpreted by highlighting their relevance to the patriarchal context in Jordan [38]. Correspondingly, the study of Haddad et al. (2011) that targeted (175) Jordanian women confirmed that (30) percent of the lifetime abuse came from the woman's brother; and this according to authors, can be explained because of the dominant patriarchal culture in Jordan [39]. From their side, Abujilban et al. (2015) and Clark et al. (2009) emphasized that IPV is rooted in the Jordanian culture and widely accepted among married women, they stressed on the idea that the supportive attitudes of women to obey their husbands, increase their vulnerability to violence [40]-[41].

Likewise, Haj-Yahia in his article (2002) that targeted (356) Jordanian women, presented a conclusion that women tend to accept beating from their husbands as they consider it a personal problem. The results of this article emphasized on the patriarchal ideology that prevails in the Jordanian society and its role in the occurrence and re-occurrence of wife-beating [42]. Similarly, Linos et al. (2010) article revealed that (87.5) percent of Jordanian women justify wife beating. Findings showed that the acceptance of wife beating was negatively associated with women's empowerment variables, including decision-making, education and employment. The results of this article supported researchers to understand why women in patriarchal society like Jordan may justify wife beating [43].

Another article of Haj-Yahia (2005) that targeted (349) Jordanian men, showed that there is a correlation between men's patriarchal ideology and their beliefs about wifebeating. The results showed that high percentages of Jordanian men tended to justify wife abuse, and to blame women for violence against them [44]. Alike, the article of Al Matalka and Al Hussainat (2013) that aimed to study the attitudes of (2216) Jordanian youth towards violence against women highlighted that violence against women in the Jordanian society can be understood because of the patriarchal system that aims to maintain power, control, and dominance of husband over wife [45].

Finally, the results of the articles conducted by Gharaibeh and Oweis (2009) and Oweis et al. (2009) indicated that Jordanian women are strongly bound by traditions and cultural rules and lack all means of empowerment, and affirmed that women justify, normalize and tolerate abuse due to their cultural values and norms [46]- [47].

Figure 2 shows that (30) percent of the selected articles under the category of intimate partner violence, strongly confirm the role of patriarchy in the incidence of intimate partner violence in Jordan and this was clearly referenced in the findings and conclusion part of articles. The same percentage goes for the selected articles that discuss the relationship between patriarchy and intimate partner violence only as part of the literature and theoretical review. (40) percent of the articles do not evidently mention the role of patriarchy in the existence of intimate partner violence in Jordan. It is worth mentioning that the study of Haj-Yahia (2005) is the only article that explicitly cited the word "patriarchy" in its title.

Broadly, the review of the selected articles showed that Intimate Partner Violence (IPV) is a serious public health problem in Jordan. According to articles referenced as [38], [41], [47], [45], and [40], it is essential for policy makers, women activists and community leaders to work together to 
come up with a holistic response to eradicate IPV through changing the behavior and attitudes of the Jordanian society towards this phenomenon, and educating women to change their sociocultural perceptions of marital relations. Initially, this can be done through designing and implementing programs and/or initiatives that focus on providing accurate information about the causes of wife abuse and its consequences for the woman, her children, and her family. Furthermore, appropriate prevention and interventional services should be developed to deal with the problem of abused women.

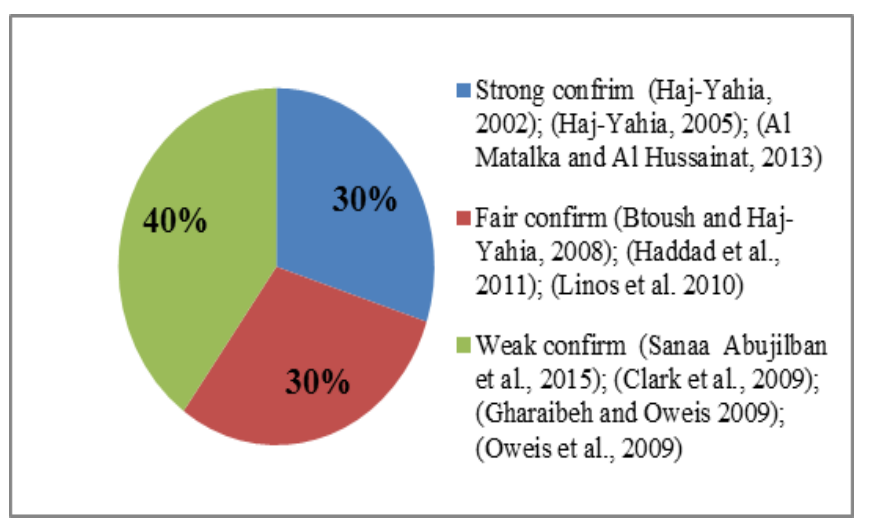

Fig. 2: Percentage of articles that confirm the role of patriarchy in the incidence of Intimate Partner violence in Jordan based on a developed scale of (Strong, Fair, Weak)

\section{Street Harassment}

According to Bowman (1993) street harassment encompasses a wide variety of behaviors, gestures, and comments. It has some defining characteristics: 1) the targets of street harassment are female; 2) The harassers are male; 3) The harassers are unacquainted with their targets; 4) The encounter is face to face; 5) The forum is a public one, such as a street, sidewalk, bus, bus station, taxi or other place to which the public generally has access; but 6) the content of the speech, if any, is not intended as public discourse [48]. Anthropologist Micaela di Leonardo (1981) has defined street harassment as:

"Street harassment occurs when one or more strange men accost one or more women in a public space which is the woman's/ women's worksite. Through looks, words, or gestures the man asserts his right to intrude on the woman's attention, defining her as a sexual object, and forcing her to interact with him" [49].

In Jordan, and according to the Jordanian Department of Statistics, there are few accessible statistical studies that show the exact prevalence of street harassment against women [50].However, this does not mean that street harassment in Jordan does not exist. Khader, the secretary of the Jordanian National Commission (JNCW) has argued that street harassment is an increasingly problem in Jordan, and admits that the Jordanian penal code does not sufficiently address the issue. In 2000, Kawar published an article on the impact of paid work on young women's lives in Jordan which mentioned that there is a fear and anxiety among many young women in Jordan about being on their own in public spaces "When I am walking alone in the street, I feel everyone is watching me." [51].

There are limited researches that address any kind of sexual harassment that occurs outside of the workplace setting in Jordan, thus, it was difficult to find any connection between patriarchy and street harassment in Jordan. Only one article was found -Truluck (2015)- that discusses street harassment among Jordanian and Syrian refugees but without linking its causes or incidence to the concept of patriarchy. The results of the article of Truluck (2015) showed that (72) percent among the Jordanian and Syrian refugee participants had experienced sexual harassment in a public place during 2014. There was no statistically significant difference in how many respondents from each nationality had experienced street harassment during 2014 [52]. It is better to accept that much research efforts should be put on this type of violence against women. From the standpoint in question, then, theorists like Bowman (1993) claimed that street harassment is another way to put women in their traditional place and keep them out of the public scope. Also, Sheffield (1989), argued that "street harassment is just one form of "sexual terrorism" used by some men and boys to frighten, dominate and control women and girls [53].

\section{SUMMARY OF FINDINGS}

Findings show that (33) percent of the selected articles strongly mention the role of patriarchy in the incidence of gender-based violence in Jordan under its three main types (Honor-based Violence, Intimate Partner Violence and Street Harassment) and this was clearly referenced in the findings and conclusion part of the articles, (38) percent of the selected articles discuss the relationship between patriarchy and gender-based violence only as part of the literature and theoretical review, while (29) percent of the articles do not evidently mention the role of patriarchy in the occurrence of gender-based violence in Jordan.

It may be reasonable to sum up that this systematic review of the research literature indicates that gender-based violence continues to occur in Jordan. Findings of one third of the articles clearly demonstrate that the patriarchal perspective best describes the reason for the incidence of gender-based violence against women in Jordan (Eisner and Ghuneim, 2013; Cinthio and Ericsson, 2006; Chesler and Bloom, 2012; Hartman, 2010; Haj-Yahia, 2002; Haj-Yahia, 2005; Al Matalka and Al Hussainat, 2013). Notwithstanding the low percentage of articles that affirmed the role of patriarchy in the incidence of gender-based violence in Jordan and the limited number of articles that were found strongly discussing this argument, this paper supports to build a debate that will pave the way for researchers to conduct future researches that are based on empirical primary data under the objective of exploring the inter-relationship between patriarchy and genderbased violence. 


\section{VIII.CONCLUSION AND WAY FORWARD}

It is difficult to generalize with confidence that patriarchy plays a vital role in the incidence and continuation of genderbased violence against women in Jordan, but it is without any doubt, a rooted element that determines the manifestations of this societal phenomenon. It is worth mentioning that the findings of the systematic review of the literature showed that honor-based violence is the most likely to be interpreted through the lens of patriarchy. This paper documents a lack in the number of phenomenological studies that are being implemented to analyze gender-based violence in Jordan, studies on how fundamentally gender-based violence overlaps with patriarchy, socio-geopolitical and economic variables and factors are limited. Much more primary research is required on this subject, which remains extremely sensitive.

It has been shown that feminism theorists largely concur in treating patriarchy as the main cause or one of factors for the occurrence of gender-based violence against women. They argue that because men view women as fundamentally different from themselves, women and girls are reduced to the status of the second sex and hence being subordinated, marginalized, excluded and victimized.

Jordan is still among the Middle Eastern Arab societies that are defined as part of the "patriarchal belt", hence, women emancipation in Jordan is still seen as a threat to this patriarchal system which holds the upper hand against any conduct or behavior of women that challenges its domination. Gender-based violence against women is growing in Jordan, but obviously it is not one of the country's priorities at the current time because security has justifiably become the prime importance in a region that is overwhelmed with human disasters like civil wars, refugee crises, political chaos, economic depression, and systemic youth un-employment.

Consequently, to eradicate gender-based violence in Jordan, a holistic approach should be adopted to overcome patriarchy and other factors associated with this social phenomenon. It is urgent to protect women from patriarchy through strengthening their social, economic and political position. This can be done through; First: enhancing the school environment and the overall learning experiences as these are the first platforms for building concepts, beliefs, values, mindsets and internalizing gender identity. It is very crucial to take into account gender sensitivity when designing and developing the educational curricula, as removing the historical and cultural contributions of women from the curricula, may build generations that are situated uncertainly between equality mottos and practices rooted in the gender gaps and absence of equality. Second: promoting women friendly constitutions and legal frameworks. The Jordanian government has to step now in and work on amending the Article 6 of the Constitution to guarantee equal rights to all its citizens, regardless of their sex. Without this, women will be continue to be treated disrespectfully. Third: encouraging women to participate in the labor market and become economically empowered. According to the World Bank
(2014), the participation of Jordanian women in the labor market is only (22) percent versus (87) percent for men. Gender-related bias in the economic structure of employment adversely affects women's economic participation. Also the family, which is the unit of stratification in Jordan, plays a role in giving certain family members, predominantly males, the opportunity to enter the labor market, thus, making their position within the class structure more determined in compared to females. Fourth: combatting stereotyped practices and taboos that oppress Jordanian women. The disadvantage of women in the Jordanian society is attributed mainly to stereotyped customary expectations, held by both men and women, that keep women back from professional advancement, prevent them to enter the male dominated professions and retain them inside the circle of what so-called semi-professions. It is also important to challenge the culturally-based practices that promote son preference, and work to change the patriarchal division of labour in the home through advocating equitable distribution of housework.

Although in some conservative places, discussing gender-based violence is still a joke, but there is a big confidence that change is underway. Jordanian women need to recognize that the voice of millions is more powerful than the appeals of few isolated voices. There is a necessity to tell the stories of victimized women not just statistics, because this will help us to understand gender-based violence in a better way. This paper is a call for action for all Jordanian women because all are victims of the conventional definition of gender roles- to stand-up, to empower themselves and others, to be change agents towards a society without any form of victimization.

\section{ACKNOWLEDGMENT}

I would like to express my thanks to those who offered constructive comments on this article. This paper is dedicated to all Jordanian women who work on empowering themselves for a society free from any forms of gender-based violence.

\section{REFERENCES}

[1] UN Declaration on the Elimination of Violence against Women, art.1.

[2] UNFPA, Fact sheet on Gender-based Violence, UNFPA official site in Jordan, May 16, 2017, http://arabstates.unfpa.org/en/publications/jordan-fact-sheet-genderbased-violence. (accessed November 2, 2017).

[3] Sylvia Walby, "Theorizing Patriarchy” (Oxford: Blackwell, 1990).

[4] Gerda Learner, "The Creation of Patriarchy" (New York: Oxford University Press, 1987), 239.

[5] Heidi Hartmann, "Capitalism, Patriarchy, and Job Segregation by Sex", Signs: Journal of Women in Culture and Society 1, no. 3, Part 2 (1976): 138.

[6] Kate Millet, "Sexual Politics" (Urbana: University of Illinois Press, 2000).

[7] Juliet Mitchell, "Psychoanalysis and Feminism: Freud, Reich, Laing and Women" (New York: Vintage Books, 1974.

[8] Michel Foucault, "Madness and Civilization: A History of Insanity in the Age of Reason"( New York: Vintage Books, 1973).

[9] Emerson Dobash and Russell Dobash, "Violence Against Wives: A Case Against the Patriarchy" (New York: Free Press, 1979).

[10] Sylvia Walby, "Theorizing Patriarchy" ........ supra footnote 3. 
[11] Gewn Hunnicutt, "Varieties of Patriarchy and Violence against Women Resurrecting "Patriarchy" as a theoretical tool" ,Violence Against Women 15, no.5 (2009): 553-573 https://doi.org/10.1177/1077801208331246

[12] Emerson Dobash and Russell Dobash, "Violence Against Wives: A Case Against the Patriarchy" (New York: Free Press, 1979); Valentine M Moghadam, "Patriarchy in Transition: Women and the Changing Family in the Middle East", Journal of Comparative Family Studies 35, no. 2 (2004): 137-162.

[13] Craig Lockard, " Societies, Networks, and Transitions: A Global History" (Boston: Cengage Learning, 2007), 111-114.

[14] Abdul Hadi, "Patriarchy and Gender-based Violence in Pakistan", European Journal of Social Sciences Education and Research 10, no.8 (2017): 298.] https://doi.org/10.26417/ejser.v10i2.p297-304

[15] Ann Tickner, "Patriarchy" (Oxford, UK: Taylor \& Francis, 2001), 1197-1198.

[16] Bonnie J. Fox, "Conceptualizing 'Patriarchy", Canadian Review of Sociology 25 , no. 2 (1988):163-182 https://doi.org/10.1111/j.1755-618X.1988.tb00101.x

[17] Radford Jill and Elizabeth A. Stanko, "Violence Against Women and Children: The Contradictions of Crime Control Under Patriarchy", in Stenson and Cowell (eds.), The Politics of Crime Control (London: Sage, 1991), 186-202.

[18] Audre Lord, "The Master's Tools Will Never Dismantle the Master's House", in Moraga and Anzaldúa (eds), This Bridge Called My Back: Writings by Radical Women of Color (New York: Kitchen Table Press, 1983), 94-101.

[19] Isam Shihada, "The Patriarchal Class System in Nawal El Saadawi's God Dies by the Nile", Nebula Journal, no.10 (2007):162-182.

[20] Souissi Alasdair, "Women Challenge 'Honor' Killings", The Christian Science Monitor, March 2, 2005, http://www.csmonitor.com/2005/0302/p15s01-wome.html. (accessed November 5, 2017).

[21] Human Rights Watch, "Violence Against Women and "Honor" Crimes", Human Rights Watch News, April 6, 2011, http://pantheon.hrw.org/legacy/press/2001/04/un_oral12_0405.htm. (accessed November 5, 2017).

[22] Suzanne Ruggi, "Commidifying Honor in Female Sexuality: Honor Killings in Palestine", Middle East Report, no. 2006 (1998): 12-15.

[23] Adam Coogle, "Recorded "Honor' Killings on the Rise in Jordan: Alarm Grows with 26 murders so Far This Year", Human Rights Watch Site. October 27, 2016, https://www.hrw.org/news/2016/10/27/recorded-honor-killings-risejordan. (accessed November 7, 2017)

Kathryn Christin Arnold, "Are the Perpetrators of Honor Crimes Getting Away with Murder?: Article 340 of the Jordanian Penal Code Analyzed Under the Convention of the Elimination of All Forms of Discrimination Against Women", American University International Law Review 16, no. 5 (2001): 1345.

[24] Manuel Eisner and Lana Ghuneim, "Honor Killing Attitudes Amongst Adolescents in Amman, Jordan", Aggressive Behavior 39,(2013): 405417. https://doi.org/10.1002/ab.21485

[25] Ellen Sheeley, "Reclaiming Honor in Jordan: A National Public Opinion Survey on Honor Killings" (Dubai: Black Iris Publishing, 2007).

[26] Faqir, Fadia., "Interfamily Femicide in Defence of Honour: The Case of Jordan", Third World Quarterly 22, no.1 (2001): 56-82. https://doi.org/10.1080/713701138

[27] Hanna Cinthio and Marcus Ericsson, "Beneath the Surface of Honour: A study on the interplay of Islam and tribal patriarchy to crimes of honour in Jordan" (Lund University, 2006).

[28] Saif Al Rawhi, "Honour-based Killings: Conceptual Framework", South East Asia Journal of contemporary Business: Economic and Law 11, no.4 (2016).

[29] Andrzej Kulczycki and Sarah Windle, "Honor Killings in the Middle East and North Africa: A Systematic Review of the Literature", Violence Against Women Journal 17, no.11 (2012): 1455.

[30] Phyllis Chesler and Nathan Bloom, "Hindu Vs. Muslim Honor Killings", Middle East Quarterly 19, no.3 (2012): 43-52.
[31] Ebtihal Mahadeen, "The martyr of dawn': Femicide in Jordanian Media", Crime, Media, Culture Journal 13, no. 1 (2016): 41-54. https://doi.org/10.1177/1741659016643120

[32] Danielle M. Becknell, "Gender Based Violence in Jordan: Domestic Violence and Honor Crimes" .Independent Study Project (ISP) Collection (2005).

[33] Krysten Hartman, "The Shame of Preserving Honor: Why Honor Killings Still Plague the Hashemite Kingdom of Jordan in the 21st Century" (Claremont McKenna College, 2010).

[34] WHO, "Understanding and Addressing Violence Against Women: Intimate Partner Violence", WHO official site, 2012, http://apps.who.int/iris/bitstream/10665/77432/1/WHO_RHR_12.36_en g.pdf. (accessed November 10, 2017)

[35] Angie Boy and Andrzej Kulczycki, "What we know about intimate partner violence in the Middle East and North Africa" Violence Against Women 14, no.1 (2007): 53-70. https://doi.org/10.1177/1077801207311860

[36] UN Women, "Global Database on Violence against Women", UN Women official site,2016, http://evaw-globaldatabase.unwomen.org/en/countries/asia/jordan\#2. (accessed November 10, 2017).

[37] Rula Btoush. and Muhammad Haj-Yahia, "Attitudes of Jordanian Society Toward Wife Abuse", Journal of Interpersonal Violence 23, no.11 (2008): 1531-1554. https://doi.org/10.1177/0886260508314313

[38] Linda Haddad et al., "Screening for Domestic Violence in Jordan", International Journal Women's Health, no. 3 (2011): 79-86. https://doi.org/10.2147/IJWH.S17135

[39] Sanaa Abujilban et al., "Effects of Intimate Partner Physical Violence on Newborns' Birth Outcomes Among Jordanian birthing Women", Journal of Interpersonal Violence 32, no. 24 (2015): 3822-3838. https://doi.org/10.1177/0886260515603975

[40] Cari Clark et al., "Violence During Pregnancy in Jordan: Its Prevalence, Associated Risk and Protective Factors", Violence against Women 15, no.6(2009):720-735. https://doi.org/10.1177/1077801209332191

[41] Muhammad Haj-Yahia, "Beliefs of Jordanian Women about WifeBeating", Psychology of Women Quarterly, 26 (2002): 282-291. https://doi.org/10.1111/1471-6402.t01-1-00067

[42] Natalia Linos et al., "Women's Autonomy and Support for Wife Beating: Findings From a Population-Based Survey in Jordan", Violence and Victims 25, no.3 (2010):409-419 https://doi.org/10.1891/0886-6708.25.3.409.

[43] Muhammad Haj-Yahia, "Can People's Patriarchal Ideology Predict their Beliefs about Wife Abuse", The Journal of Community Psychology 33, no. 5 (2005): 545-567. https://doi.org/10.1002/jcop. 20068

[44] Faisal Al-Matalka and Mohammad Hussainat, "Attitudes of Jordanian Youth towards Violence against Women", Asian Social Science Journal 9, no. 3 (2013): 192-201. https://doi.org/10.5539/ass.v9n3p192

[45] Muntaha Gharaibeh and Arwa Oweis, "Why Do Jordanian Women Stay in an Abusive Relationship: Implications for Health and Social WellBeing", Journal of Nursing Scholarship 41, no. 4 (2009): 376-384 https://doi.org/10.1111/j.1547-5069.2009.01305.x

[46] Arwa Oweis et al., "Unveiling the Suffering of Women With a Low Income in Jordan", Journal of Transcultural Nursing 20, no. 1(2009): 69-76. https://doi.org/10.1177/1043659608325848

[47] Cynthia Bowman, "Street Harassment and the Informal Ghettoization of Women", Harvard Law Review 106, no. 3 (1993)106: 517-580.

[48] Michaela di Leonardo, "Political Economy of Street Harassment", AEGIS, (1981): 51-57.

[49] Elizabeth Whitman, "The Silent Scourge", The Nation, April 7, 2014, https://web-bebscohostcom.proxy.library.emory.edu/ehost/detail/detail?vid=3\&sid=5 278a4f5-38ff-4867b2645f696f548603\%40sessionmgr115\&hid=123\&bdata=JnNpdGU9ZWhvc 3QtbGl2ZQ\%3 d\%3d\#db=a9h\&AN=95055427. (Accessed November $11,2017)$ 
[50] Mary Kawar, "Transitions and Boundaries: Research into the Impact of Paid Work on Young Women's Lives in Jordan", Gender and Development 8, no.2 (2010) 56-65. https://doi.org/10.1080/741923629

[51] Emilia Truluck, "Understanding Street Harassment in Jordan: A Comparative Analysis of Syrian Refugees' and Jordanian Citizens' Experiences of Street Harassment in Jordanian Host Communities", SIT Study Abroad, (2015).

[52] Carole Sheffield, "The Invisible Intruder: Women's Experiences of Obscene Phone Calls", Gender and Society 3, no. 4(1989): 483. https://doi.org/10.1177/089124389003004006 